\title{
O ENSINO DE ARTE E AS HIBRIDIZAÇÕES CULTURAIS: NOVAS PERSPECTIVAS PARA A EDUCAÇÃO ESTÉTICA DO SÉCULO XXI
}

\author{
Maria Brígida Valentim Portela, Genivaldo de Souza Santos \\ Universidade do Oeste Paulista- UNOESTE, Mestrado em Educação, Presidente Prudente, SP. e-mail: \\ m.brigida@gmail.com. CAPES/PROSUP.
}

\section{RESUMO}

Este trabalho tem sua origem na pesquisa de mestrado em educação, que trata do ensino de arte e as hibridizações culturais. Seu objetivo é investigar a presença da hibridização cultural nas propostas educativas pós-modernas para o ensino de arte, a partir das discussões curriculares surgidas a partir da década de 1980, e mais especificamente problematizar o conceito de hibridismo cultural e possíveis efeitos na prática docente, no ensino de arte. Tratando-se de um estudo exploratório, descritivo e analítico escolhemos a pesquisa qualitativa como abordagem e o instrumental metodológico da pesquisa bibliográfica. Esperamos com este estudo contribuir para a pesquisa acadêmica sobre o ensino de arte e para a compreensão da hibridização cultural neste ensino, como uma construção histórica e social, dinâmica na qual a escola está inserida. Não há como refletir sobre cultura, principalmente, em se tratando de projetos educacionais, sem encarar as desigualdades e as multiplicidades do nosso tempo.

Palavras-chave: ensino de arte; docência; hibridação cultural.

\section{EDUCATION OF ART AND CULTURAL HYBRIDIZATION: NEW PERSPECTIVES FOR THE AESTHETIC EDUCATION OF XXI CENTURY.}

\begin{abstract}
This work has its origin in the research master's degree in education, which deals with the teaching of art and cultural hybridizations, whose goal is to investigate the presence of cultural hybridization in postmodern art education for the educational proposals, from the curricular discussions emerged the from the 1980s, and further specifically problematize the concept of cultural hybridity and possible effects on teaching practice in the teaching of art. Since this is an exploratory, descriptive and analytical study chose qualitative research as the methodological approach and the instrumental literature. We hope with this study contribute to the academic research on the teaching of art and understanding of cultural hybridization in this school, as a social and historical construction, dynamic in which the school is located. There is no way a reflection on culture, especially when it comes to educational projects, without facing inequalities and multiplicities of our time.
\end{abstract}

Keywords: Art Education; teaching; cultural hybridization. 


\section{INTRODUÇÃO OBJETIVO}

$\mathrm{O}$ ensino de arte, ao ser inserido e reconhecido nos currículos escolares como um campo de conhecimento, pode tornar-se um espaço privilegiado para o desenvolvimento de uma educação inclusiva no seu sentido mais amplo, respeitando as individualidades pessoais e as características dos diferentes grupos que compõem 0 ambiente escolar, proporcionando aos sujeitos envolvidos no processo educacional, um verdadeiro encontro de culturas, que ao combinarem-se poderão deixar evidentes a heterogeneidade da nossa sociedade e isto, pode propiciar uma educação mais justa e igualitária para todos.

Se considerarmos $\mathrm{o}$ ato de educar como um ato essencialmente humano, nos parece fundamental a compreensão da realidade cultural na qual estamos imersos cujas características se mostram, transcultural, não linear, mas hibrida e convergente. Essa realidade para Barbosa (2008) faz parte do mundo "complexificado do século XXI onde todas as dimensões parecem fundidas e os limites- até mesmo das alegorias simples ao sagrado e o profano - parecem cada vez menos indistintos". (BARBOSA, 2008, p.10). Assim, perceber as nuances culturais do mundo pós-moderno, especialmente do campo da educação é "participarmos de uma experiência total, diretiva, política, ideológica-gnosiológica, pedagógica, estética e ética, em que a boniteza deve achar-se de mãos dadas com a docência e a seriedade" (FREIRE, 1996, p.24).

No que se refere ao ensino da arte, não podemos esquecer que sua institucionalização é bastante recente na História da Educação. Instituído oficialmente no currículo escolar como atividade, a arte chega às escolas com o caráter eminentemente tecnicista e polivalente decretado "[...] pelo período ditatorial da década de 1970, pela Lei de Diretrizes e Bases 5692/71" (BARBOSA, 2008, p.23) e, somente em 1996 com Lei de Diretrizes e Bases- 9496/96- ela passa a ser reconhecida como disciplina obrigatória com conteúdos próprios ao campo epistemológico da Arte. Para Barbosa, esse reconhecimento foi uma conquista para o ensino de arte, porém “[...] a mera obrigatoriedade e o reconhecimento da necessidade não são suficientes para garantir a existência da Arte no currículo" (BARBOSA, 2008, p.15).

Não é raro encontrarmos ainda hoje nas escolas, práticas eminentemente tecnicista, livre expressão ou mesmo reprodução de modelos. Para romper com essa visão e formas de ensino para Barbosa (2008), é necessário políticas públicas que garantam aos professores, formação e meios para o desenvolvimento da capacidade de compreender, conceber e fruir arte. Para essa autora "[...] sem a experiência e o 
conhecimento em arte, por parte de professores e alunos, nenhuma teoria de Arte/Educação será reconstrutora." (BARBOSA, 2008, p. 14).

Neste sentido para o desenvolvimento da pesquisa nos apoiamos nas discussões curriculares surgidas a partir da década de 1980, que insere a interculturalidade como um dos princípios norteadores para a educação estética dos estudantes e nos baseamos em referenciais teóricos como: Néstor Garcia Canclini (2006) que considera a hibridização cultural como "processos socioculturais nos quais estruturas e práticas discretas, que existiam de forma separada, se combinam para gerar novas estruturas, objetos e práticas" (CANCLINI, 2006, p. 19) ; Jesus Martín Barbero (1999), que em consonância com Canclini, no seu livro "Dos meios às mediações- comunicação, cultura e hegemonia", afirma que o encontro da educação com outros campos de saberes/culturais abrem possibilidades para a configuração de novas estéticas; Roger Chartier (1991) sobre representações nos processos educacionais, evidenciadas na linguagem dos atores, nas palavras que usam, na consciência que têm das suas percepções e determinações sociais que não são homogêneas, mas ações "pelas quais os indivíduos e os grupos dão sentido ao mundo que é o deles" (CHARTIER, 1991, p. 177) e
Ana Mae Barbosa (2008), que compreende o encontro das diferentes culturas como uma comunidade de sentidos de pertinência e pertencimento daqueles que a compõem comportando, portanto, transfusões e mestiçagens entre as mesmas.

Nesta perspectiva, os objetivos desse trabalho é investigar a presença da hibridização cultural nas propostas educativas pós-modernas para o ensino de arte, a partir das discussões curriculares surgidas na década de 1980, e mais especificamente problematizar o conceito de hibridismo cultural e possíveis efeitos na prática docente, no ensino de arte.

\section{METODOLOGIA}

Por trata-se de um estudo exploratório, descritivo e analítico nos pautamos pela abordagem qualitativa, que melhor atendeu aos objetivos, pois a mesma requer do pesquisador a adoção de uma postura hermenêutica, que na perspectiva gadameriana (2011), procura ultrapassar qualquer suposição de que os processos interpretativos são marcados pelo intuito primordial de alcançar a verdade previamente dada e instituída.

$\mathrm{O}$ ato de pesquisar por si só carrega consigo um processo de desaprendizagem e nesse processo precisamos, muitas vezes, abandonar as nossas crenças, passar por experiências nunca imaginadas e caminhar 
(Masschelein, 2008) por trilhas e lugares antes nunca vistos ou vistos e nunca observados. Neste processo, descobrimos novos autores e referenciais teóricos que foram suporte para as novas ideias e relações construídas no campo da educação; para a compreensão mais a fundo da história do ensino de arte no campo da educação; a linearidade e a racionalidade que transitaram e muitas vezes ainda transitam na formação do professor e na sua atuação, e perceber-se parte dessa realidade, o que solicita a adoção da postura hermenêutica por favorecer "uma interpretação significativa mediante um processo de movimento constante entre as partes e o todo, em que não há ponto absoluto de partida nem de chegada" (SANTOS FILHO, 2009, p. 43).

Neste sentido, durante a pesquisa valorizamos a heterogeneidade de perspectivas teóricas, que nos permitiu problematizar, analisar e compreender a riqueza e a diversidade inerentes ao objetivo do estudo e às nossas inquietações primeiras que originaram este trabalho.

\section{RESULTADOS}

Por ser uma pesquisa de abordagem qualitativa como resultado apontamos as possibilidades educativas para o ensino de arte, considerando que esse estudo não se encerra com esta pesquisa, cujos elementos apresentados pedem um aprofundamento na compreensão sobre o ensino de arte, especialmente no que se refere à hibridização cultural. Esperamos que as reflexões desenvolvidas por nós possam alimentar discussões e fomentar grupos de educadores que acreditam na possibilidade de uma mudança substancial no ensino de arte realizado no nosso país, optando por uma educação voltada para o sensível que existe dentro de cada um, contextualizado ao processo ensino-aprendizagem à multiplicidade cultural, objetivando-se, contudo, a construção de conhecimento em arte.

\section{DISCUSSÃO}

A educação e o ensino de arte, enquanto campos de ensino e aprendizagem compõem a formação estética do sujeito na educação formal. Esse viés da arte na escola surge a partir da década de 1980 , oriundas das mudanças curriculares quando começaram a surgir novas possibilidades pedagógicas, frutos das pesquisas e estudos acadêmicos. Esses novos estudos propõem práticas educativas, que a nosso ver, atualizam o ensino da arte e geram experiências estéticas que Aguirre (2009, p.6) considera como "relatos abertos à pesquisa criativa".

Essa visão sobre o ensino de arte têm mobilizado estudos distintos agregando-a a 
outros campos de conhecimento como a filosofia, sociologia, antropologia, comunicações e à própria educação o que facilita e propicia cada vez mais a criação de um mapa empírico-conceitual que se aproxima da realidade pós-moderna, mediada pelas tecnologias. Para Aguirre (2009), esta aproximação dos diferentes campos do conhecimento com a arte é muito bem vinda, caso seja feita não com o intuito de compreender as obras de arte como um texto cifrado a ser desvendado, mas como "[...] um condensado de experiência gerador de uma infinidade de interpretações, porque a essência e o valor da arte não estão nos artefatos em si, mas na atividade experienciada, através da qual foram criados e são percebidos ou utilizados" (AGUIRRE, 2009, p.6).

Assim, a partir da década de 1980, um novo cenário começa a ser desenhado para o ensino de arte, pelas mudanças curriculares e principalmente pelo surgimento da Abordagem Triangular, que vem sendo sistematizada desde aquela época pela pesquisadora e autora em arte-educação Ana Mae Barbosa. Na atualidade a autora a denomina como manifestação pós-moderna para o ensino da arte, cuja premissa é a leitura critica do mundo. Barbosa (2011) marca assim os primeiros movimentos para inserir a arte como campo de conhecimento dentro do universo da Educação. Conforme ela afirma (BARBOSA, 2011, p. 5), a manifestação pós-moderna para o ensino de arte,

[...] se revigora em sintonia com a pós-modernidade, resultado do amadurecimento de um campo de conhecimento que desenvolve pesquisas e busca se aproximar do campo das práticas artísticas. Chegamos a nossa contemporaneidade que caracteriza por múltiplas deglutições e apropriações de modelos, por trânsitos entre culturas.

A revigoração proporcionada pela abordagem triangular trouxe consigo novas propostas e abordagens para o ensino de arte na contemporaneidade e, junto com as mesmas uma olhar mais afinado para realidade cultural vigente que se mostra híbrida e complexa.

\section{A hibridização cultural e a arte: das contradições à transculturação.}

A alternância e a inquietação faz parte do homem desde o seu surgimento na terra, quando percorre as cavernas deixando suas marcas e formas de expressar-se diante da natureza. Da necessidade de expressar-se e comunicar-se surgiu a linguagem, e desde então as trocas, as combinações e as apropriações culturais de diferentes grupos sociais foram aos poucos se naturalizando, ou 
como define Canclini (2006) "hibridizandose".

Portanto, o conceito de hibridização

De acordo com Canclini (2006) o termo hibridação, foi utilizado desde as civilizações antigas sendo mencionada pela primeira vez no processo migratório ocorrido na Roma antiga, e a mestiçagem no Mediterrâneo, data desde os tempos da Grécia clássica e posteriormente espalha-se pela Europa e caminha em direção à América. No entanto, as discussões e análises sobre as hibridizações em diversos processos culturais intensificaram-se nas ultimas décadas do século $X X$ e início do século $X X I$, e são identificados por diversos autores em diferentes campos do conhecimento.

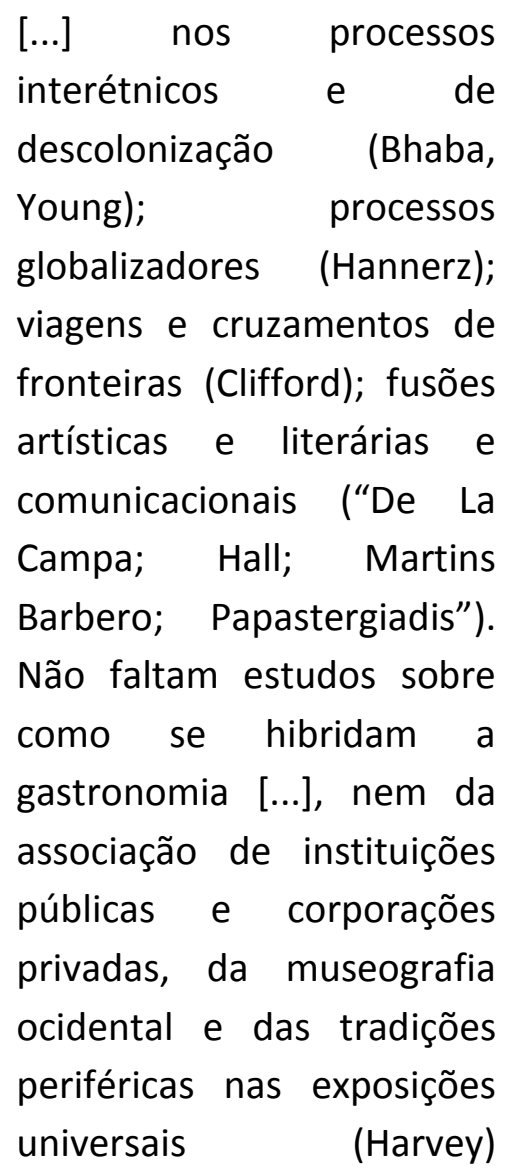

(CANCLINI, 2006, p. XVIII). cultural ou culturas híbridas são empregados largamente na contemporaneidade, facilitados e acentuados pela globalização e pelas tecnologias comunicacionais, cada vez mais presente no cotidiano e na vida das pessoas. As tecnologias da informação favorecem a veiculação de informações e acontecimentos em tempo real, sem fronteiras ou demarcações de territórios, sem limites de acesso, e este fenômeno possibilita cada vez mais que a hibridez seja um processo naturalizado e incorporado às práticas sociais.

Para Canclini (2006) nem sempre essa combinação cultural ou hibridização acontece de forma planejada ou com resultado esperado, os acasos e os imprevistos são incorporados naturalmente gerando novas combinações em um continuum, frequentemente surgidos da criatividade individual ou de grupos. Este processo de misturas não acontece somente nas artes, mas em outros campos do conhecimento.

Nas artes "[...] a primeira condição para distinguir as oportunidades e os limites da hibridação é não tonar a arte e a cultura recursos para o realismo mágico da compreensão universal" (CANCLINI, 2006, p. XXII), mas torná-la um campo onde não há certezas. Neste aspecto de acordo com 
Canton (2009), a arte na pós-modernidade enfatiza a alternância e a multiplicidade existente no campo cultural e artístico e "se materializa a partir de uma negociação entre arte e vida, vida e arte" (CANTON, 2009, p.49). Para a autora, o campo das artes hoje abarca diferentes áreas de conhecimento e aproxima-se cada vez mais das questões artísticas e estéticas surgidas no cotidiano, trazendo à tona as diferentes instâncias do corpo, a política, a ecologia, a ética e as imagens geradas pelas tecnologias da informação.

Dessa aproximação e mestiçagem é gerada a multiplicidade de linguagens e formas artísticas que geram narrativas não lineares, que não compõem a tríade começomeio-fim, mas se constituem de fragmentos temporais, sobreposições de imagens, repetições e deslocamentos que "[...]facilita revisar a separação entre o culto, o popular, o massivo [...] elaborar um pensamento mais aberto para abarcar as interações e integrações entre os níveis, gêneros e formas das sensibilidade coletiva" (CANCLINI, 2006, p.28).

Portanto, as hibridizações culturais permeiam todas as instâncias da vida contemporânea, e no espaço escolar elas se tornam ainda mais visíveis na heterogeneidade dos estudantes, que trazem consigo referências culturais vivenciadas no ambiente onde convivem, veiculadas nos meios de comunicação de massa como a televisão e mais intensamente na Internet favorecendo a transculturação e inclusão dos indivíduos em outras realidades culturais.

\section{CONSIDERAÇÕES FINAIS}

Consideramos que a arte na educação é imprescindível porque é por meio dela que compreendemos o mundo e as formas sensíveis que compõem a humanidade no sentido amplo, transcultural. Esse entendimento contribui para uma melhor arquitetura da sociedade e do indivíduo e os objetos artísticos, por si só trazem intrínsecos a história da humanidade e sua evolução, portanto é um conhecimento a que todos têm direito, especialmente, aqueles que se encontram em processo educacional.

Por isso, faz-se necessário compreender que o seu ensino, como qualquer outro campo do conhecimento, faz parte do currículo escolar e pode ser pensado de forma coerente com a realidade dos estudantes, que convivem com as tecnologias da comunicação, com um mundo mediado por imagens e com as mestiçagens próprias da sociedade. A relativização da pósmodernidade, apontada por Canclini (2006) traz consigo a facilidade de aproximação entre o culto, o popular e o massivo e, isso no contexto escolar pode ser um facilitador para o desenvolvimento de práticas educativas que permitam "elaborar um 
pensamento mais aberto para abarcar interações e integrações entre os níveis, gêneros e formas de sensibilidade coletiva" (CANCLINI, 2006, p.28).

Neste sentido, estudar e compreender os processos da hibridização cultural é dar-Ihe capacidade hermenêutica, tornando-o favorável para interpretar as relações de sentido que se reconstroem nas misturas, situando-o "[...] em outra rede de conceitos: por exemplo, contradição, mestiçagem, sincretismo, transculturação e crioulização". (CANCLINI, 2006, p. XXIV). Parece-nos ser esta a realidade das nossas escolas.

\section{REFERÊNCIAS}

ARGAN, G. C. Arte moderna. Trad. Denise Bottman e Frederico Carotti. São Paulo: Companhia das Letras, 1992.

AGUIRRE, I. Imaginando um futuro para a educação artística. 2009. Trad. Inês O. Rodrigues e Danilo de Assis Clímaco.

Disponível em: . Acesso em: 20 dez 2013.

BARBOSA, A. M. Arte-educação: leitura no subsolo. São Paulo: Cortez, 2011.

\section{Arte/educação}

contemporânea: consonâncias internacionais. 3.ed. Sâo Paulo: Cortez. 2010.

Interterritorialidade:

mídias, contextos e educação. São Paulo: Ed. Senac, 2008.

Arte-educação: conflitos e

Acertos. São Paulo: Max Limonad, 1984.
. COUTINHO, R. M. Relações

pessoais com arte. Curso de Especialização REDEFOR. São Paulo: UNESP, 2011. http://www.acervodigital.unesp.br/bitstream 1123456789/40427/3/2ed art m1d2.pdf. Acesso em: 28 dez 2013.

BARBERO, J. M. Dos meios às mediações: comunicação, cultura e hegemonia. Rio de Janeiro: Ed. UFRJ, 2009. . Sujeito, comunicação e

cultura. Comunicação \& Educação, São Paulo, n. 15, p. 62- 80, maio/ago. 1999. Disponível em http://bancopublicacoes.espm.br/arquivos/s ujeito_comunicacao_e_cultura.pdf. Acesso em: 20 dez 2013.

CANCLINI, N. G. Culturas híbridas: estratégias para entrar e sair da modernidade. São Paulo: Ed. Universidade de São Paulo, 2006.

\section{CANTON, Kátia. Do moderno ao} contemporâneo. Coleção temas da arte contemporânea, São Paulo: Editora Martins Fontes, 2009.

CHARTIER, R. O mundo como representação. Estudos Avançados, São Paulo, v. 11, n. 5, p. 173-191, 1991. http://dx.doi.org/10.1590/S010340141991000100010

FERRAZ, M. H. C. T, FUSARI, M. F. R. Metodologia do ensino de arte. São Paulo: Cortez, 1999.

FREIRE, Paulo. Pedagogia da autonomia: saberes necessários à prática educativa. São Paulo: Paz e Terra.1996 (Coleção Leitura).

MASSCHELEIN, Jan. E-ducando o olhar: a necessidade de uma pedagogia pobre. Educação e Realidade, São Paulo, v. 33, n. 1, p. 35-48, jan/jun 2008.

GADAMER, H. G. A hermenêutica da obra de arte. São Paulo: Martins Fontes, 2010. 
SANTOS FILHO, J. C. Pesquisa educacional quantidade/qualidade. São Paulo: Cortez, 2009.

Recebido para publicação em 13/07/2014

Revisado em 25/07/2014

Aceito em 12/08/2014 